\title{
Uma análise da relação entre flexibilização do trabalho, exaustão emocional e engajamento dos trabalhadores
}

\author{
An analysis of the relationship between flexible work, emotional exhaustion and \\ engagement of workers
}

\author{
Harrison Bachion Ceribeli ${ }^{1}$ \\ Guilherme Barcellos de Souza Rocha ${ }^{2}$
}

\begin{abstract}
Resumo
A gestão de pessoas modernizou-se e, entre as práticas mais modernas que têm sido adotadas pelas organizações, destacase a flexibilização dos arranjos laborais. Todavia ainda não há clareza quanto ao impacto que essa prática exerce sobre todas as dimensões do comportamento humano no trabalho. Diante desse cenário, definiu-se como objetivo para esta pesquisa analisar a influência da flexibilização do trabalho sobre o engajamento e a exaustão emocional dos trabalhadores, assim como do engajamento sobre a exaustão. Para atingir o objetivo proposto, realizou-se um levantamento de campo nas cidades de Mariana, Ouro Branco e Ouro Preto, todas localizadas no estado de Minas Gerais. Para análise dos dados, optou-se pela Modelagem de Equações Estruturais. Analisando os resultados obtidos, não foi possível confirmar a influência da adoção de arranjos laborais flexíveis por parte das organizações sobre o grau de engajamento e de exaustão dos funcionários. Por outro lado, confirmou-se a relação testada entre o engajamento e a exaustão do trabalhador. Ou seja, os resultados encontrados indicam que os profissionais mais engajados estão menos sujeitos a experimentarem maior desgaste emocional em suas atividades laborais. Logo, conclui-se que os indivíduos que mobilizam seus melhores esforços e veem no trabalho uma forma de se expressar fisicamente, emocionalmente e cognitivamente, mostrando disposição ao realizarem suas tarefas, tendem a preservar (e não a drenar) seus recursos mentais.
\end{abstract}

Palavras-chave: Arranjos laborais flexíveis. Esgotamento mental do trabalhador. Engajamento do funcionário. Engajamento no trabalho.

\begin{abstract}
Human resources management has been modernized and, among the most modern practices adopted by organizations, it is worth highlighting the flexibility of the work arrangements. However, there is still no clarity about the impact that this practice has on all dimensions of human behavior at work. In view of this scenario, it was defined as objective for this research to analyze the influence of flexible work on the engagement and emotional exhaustion of workers, and the influence of engagement on exhaustion. To reach the proposed objective, a survey was carried out in the cities of Mariana, Ouro Branco and Ouro Preto, all located in the State of Minas Gerais. For the analysis of the data, were executed a Structural Equation Modeling. Analyzing the results obtained, it was not possible to confirm the influence of the adoption of flexible working arrangements by the organizations on the degree of engagement and exhaustion of the employees. On the other hand, the tested relationship between worker engagement and exhaustion was confirmed. Therefore, the results indicate that the most engaged professionals are less likely to experience greater emotional exhaustion in their work activities. Thus, it is concluded that individuals who mobilize their best efforts and see work as a way of expressing themselves physically, emotionally and cognitively, showing willingness to perform their tasks, tend to preserve (and not drain) their mental resources.
\end{abstract}

Keywords: Flexible working arrangements. Mental fatigue of the worker. Employee engagement. Work engagement.

Doutor em Administração pela Universidade de São Paulo (FEARP-USP). Professor Adjunto da Universidade Federal de Ouro Preto (UFOP). Vice-diretor do Instituto de Ciências Sociais Aplicadas (ICSA-UFOP). Brasil. Afiliação: Universidade Federal de Ouro Preto. Lattes: http://lattes. cnpq.br/8913367429929208 Email: harrisonbceribeli@hotmail.com

2 Graduando em Administração pela Universidade Federal de Ouro Preto (UFOP). Brasil. Afiliação: Universidade Federal de Ouro Preto. Lattes: http://lattes.cnpq.br/3935897340794236 Email: guilhermebarcellosrocha@gmail.com 


\section{Introdução}

Com a abertura comercial do Brasil, a competição enfrentada pelas empresas brasileiras intensificouse substancialmente. Em decorrência disso, algumas não sobreviveram, outras foram adquiridas por concorrentes locais ou multinacionais. De maneira generalizada, um amplo movimento de consolidação teve início, com fusões, aquisições e inúmeras alianças estratégicas (CAMARGOS; BARBOSA, 2003). Ao mesmo tempo, houve uma modernização do parque industrial e dos modelos de gestão adotados no país (FLEURY; FLEURY; BORINI, 2013).

No mesmo período, ocorreram, em nível internacional, crescentes avanços tecnológicos, dando origem ao que se convencionou chamar de sociedade da informação, na qual as pessoas, as informações e os conhecimentos tornaram-se o bem mais valioso para as organizações; com isso, passou-se a atribuir importância estratégica aos recursos humanos no âmbito empresarial (ALMEIDA; TEIXEIRA; MARTINELLI, 1993).

Nesse contexto, o conceito de gerir pessoas e a visão do papel dos trabalhadores no meio empresarial evoluíram, superando o arquétipo convencional de gestão, que associava os funcionários a custos que precisavam ser controlados, o qual foi substituído pela premissa de que os indivíduos são a chave para a busca de soluções para manter a competitividade dos negócios (MENESES et al., 2014;VASCONCELOS et al., 2015).

Em decorrência dessa mudança conceitual, muitos gestores passaram a implantar políticas e práticas de gestão de pessoas com o intuito de estimular nos funcionários comportamentos, atitudes e padrões de conduta que estivessem alinhados à estratégia competitiva do negócio (MASCARENHAS; BARBOSA, 2013; LEITE; LEITE; ALBUQUERQUE, 2013). Além disso, com o aumento da importância atribuída às pessoas, alguns aspectos, como o engajamento dos profissionais, passaram a ser mais observados no âmbito organizacional (PORTO-MARTINS; BASSO-MACHADO; BENEVIDES-PEREIRA, 2013; ARROWSMITH; PARKER, 2013).

O primeiro autor que adotou o termo engajamento (engagement) foi Kahn (1990), que o definiu como o nível de aproveitamento do indivíduo em relação a seu papel na organização. Ainda segundo o mesmo autor, as pessoas engajadas são aquelas que se mobilizam e se expressam fisicamente, cognitivamente e emocionalmente durante o desempenho de seus papeis no trabalho. Mais tarde, porém, no campo da Ciência Administrativa, os pesquisadores passaram a utilizar as expressões engajamento do funcionário (employee engagement) e engajamento com o trabalho (work engagement) (SCHAUFELI; SALANOVA, 2011).

Outro tema que tem despertado interesse de pesquisadores e gestores é a exaustão emocional dos trabalhadores, a qual, assim como o engajamento, afeta o desempenho organizacional (XU; HUANG; ROBINSON, 2015; RASHEED; KHAN; RAMZAN, 2013). A exaustão, que é a dimensão principal da Síndrome de Burnout (BEN-AVI; TOKER; HELLER, 2018), remete a um completo esgotamento mental do trabalhador, que reduz de maneira significativa sua produtividade (HALLIDAY et al., 2017).

Para lidar com essas novas preocupações, que incluem a busca pelo aumento do engajamento e a redução da exaustão dos indivíduos, a gestão de pessoas modernizou-se e, entre as práticas que têm sido adotadas pelas organizações, destaca-se a flexibilização dos arranjos laborais, cujo intuito é favorecer a conciliação dos interesses dos profissionais e as necessidades organizacionais (WONG; WAN; GAO, 2017; COENEN; KOK, 2014). Todaviaainda não há clareza na academia quanto ao impacto que essa prática exerce sobre todas as dimensões do comportamento humano no trabalho, o que deu origem ao seguinte problema de pesquisa: os arranjos laborais flexíveis são capazes de afetar diretamente o engajamento e a exaustão dos trabalhadores? Ademais, questiona-se se o engajamento é capaz de impactar o grau de exaustão experimentado pelos indivíduos no trabalho.

Diante desse cenário, definiu-se como objetivo para esta pesquisa analisar a influência da flexibilização do trabalho sobre o engajamento e a exaustão emocional dos trabalhadores, assim como a influência do engajamento sobre a exaustão.

A justificativa para a realização desta investigação reside em dois aspectos-chave. Primeiramente, assinala-se, com base em um levantamento bibliográfico previamente conduzido pelos presentes autores 
nas bases Spell, Scielo, Redalyc e Scopus, que, tanto na literatura nacional quanto na internacional, o impacto dos arranjos laborais flexibilizados sobre as duas dimensões do comportamento dos trabalhadores aqui exploradas ainda carece de estudos para que se obtenham conclusões consolidadas. Em segundo lugar, faz-se necessário clarificar a relação entre o engajamento e a exaustão dos indivíduos no trabalho, aumentando a compreensão a respeito de como as múltiplas facetas do comportamento humano no trabalho correlacionam-se entre si.

\section{Referencial teórico}

\subsection{Flexibilização do trabalho}

Para analisar a flexibilização do trabalho deve-se, primeiramente, compreender o contexto histórico em que ocorreu seu surgimento. Em decorrência da crise internacional de 1973-75, o setor industrial, acompanhando a instabilidade política e econômica do período, vivia um momento conturbado; as empresas enfrentavam um cenário caracterizado pela saturação dos mercados, recessão na economia e aumento da concorrência internacional (MENDONÇA, 1990). Naquele contexto, muitas empresas foram forçadas a reestruturarem seus modelos gerencias, flexibilizando sua relação com a força de trabalho. Entre as modalidades que surgiram na época, as mais comuns entre os países capitalistas incluíram a remuneração variável atrelada a bons resultados do trabalhador ou da organização e o achatamento da jornada de trabalho (DEDECCA, 1999).

Mais tarde, as discussões referentes à flexibilização da jornada de trabalho passaram a englobar, além da redução da carga horária, questões como contratos flexíveis, compensação de horas, trabalho em domicílio e extinção do controle de horário (ROHM; LOPES, 2015; KARSTEN; LEOPOLD, 2003), tudo isso com o fim de se obter maior produtividade nas organizações (GENARI; FACCIN; MACKE, 2013).

Todavia a flexibilização laboral não se deu somente devido a fatores políticos e econômicos. Segundo Vasconcelos, Furtado e Pinheiro (2015), o avanço desse movimento resultou da maior disponibilidade e velocidade da informação, do desenvolvimento tecnológico, da criação de softwares específicos e da ampliação do acesso à Internet.

Ademais, na sociedade pós-moderna, ou sociedade da informação, a utilização das novas ferramentas tecnológicas disponíveis permitiu que os indivíduos rompessem fronteiras que até então lhes eram impostas, dando-Ihes mais autonomia e uma visão de mundo ampliada. E, devido a essa revolução tecnológica e social, eclodiram pressões por mudanças nos formatos convencionais de trabalho, o que contribuiu para o surgimento de conceitos, tais como: locais flexíveis, horários flexíveis e contratos flexíveis; que, integrados, deram origem ao teletrabalho, uma das modalidades da flexibilização laboral (COLE; OLIVER; BLAVIESCIUNAITE, 2014; VASCONCELOS; FURTADO; PINHEIRO, 2015).

De acordo com Rafalski e Andrade(2015), o teletrabalho se trata de um formato de trabalho em que parte das atividades é realizada in loco e parte é realizada em local indefinido. Garrett e Danziger (2007) classificam o teletrabalho em três categorias distintas: fixed-site telework, quando os profissionais atuam a maior parte do tempo em escritórios e locais físicos da empresa; flexiwork, quando os trabalhadores atuam em múltiplos locais, nem sempre determinados pelo empregador, incluindo a própria casa, os escritórios da empresa e outros locais; e mobile telework, quando os indivíduos realizam, na maior parte do tempo, trabalho de campo em locais variáveis.

Além do teletrabalho, a flexibilização laboral pode se dar também por meio do horário flexível, prática comumente adotada por organizações que possuem uma estratégia de gestão de pessoas focada na atração, motivação e retenção de talentos-chave (HILL et al., 2008).

A flexibilização do horário de trabalho tem sido operacionalizada pelas organizações de duas formas distintas: flexi-time, quando o profissional tem a possibilidade de ajustar, junto aos gestores, como irá cumprir sua carga de trabalho mensal pré-determinada, conciliando demandas pessoais e organizacionais; e parttime work, quando o profissional tem a opção de cumprir uma jornada de trabalho reduzida, alternativa interessante para os indivíduos que não querem ou que não têm condição de cumprirem a jornada integral (BAJZIKOVA et al., 2013). 
A versatilidade na definição do local e horário de trabalho é benéfica para empregados e empregadores, pois, à medida que permite maior convívio familiar e equilíbrio entre as demandas laborais e interesses particulares, aumenta a satisfação dos indivíduos no trabalho, o que tende a afetar de forma positiva a produtividade obtida pelas organizações (COSTA, 2013; GRISCI; CARDOSO, 2014; COENEN; KOK, 2014; RAFALSKI; ANDRADE, 2017). Além disso, os arranjos de trabalho flexíveis tendem a reduzir a exaustão experimentada pelos trabalhadores (WINDELER; CHUDOBA; SUNDRUP, 2017; SARDESHMUKH; SHARMA; GOLDEN, 2012; PETERS; WILDENBEEST, 2010).

Em contrapartida, apesar de todos esses benefícios, os estudos que correlacionaram a flexibilização laboral e o engajamento dos trabalhadores encontraram uma relação negativa, indicando que, ao longo do tempo, os arranjos flexíveis de trabalho podem exercer um efeito indesejável sobre tal dimensão do comportamento humano nas organizações (TIMMS et al., 2015; SARDESHMUKH; SHARMA; GOLDEN, 2012).

\subsection{Engajamento no trabalho}

De acordo com Ouweneel, Leblanc e Schaufeli (2013), o engajamento pode ser descrito como um estado mental de contentamento que resulta em maior disposição energética, fazendo com que o indivíduo enfrente dificuldades e canalize seus esforços na realização de determinada tarefa. Nesta mesma linha, Xanthopoulou, Bakker e Fischbach (2013) descrevem o engajamento como um estado mental de satisfação contínua por parte do indivíduo, que resulta em grande potencial energético e entrega para cumprir as tarefas que lhes foram designadas.

Sob uma ótica distinta, o engajamento pode ser compreendido como um estado mental caracterizado por elevado foco no trabalho, associado a um sentimento positivo relacionado com o papel desempenhado e ações que demonstrem comprometimento com os objetivos e valores da organização (LEWIS; DONALDSONFEILDER; THARANI, 2011).

Conforme se verifica em Ouweneel, Leblanc e Schaufeli (2013), podem ser apontados como componentes do engajamento o vigor e a dedicação, sendo que o primeiro se refere ao elevado nível de energia direcionado à realização de uma tarefa, enquanto a segunda remete ao entusiasmo com que os desafios são enfrentados e o trabalho é executado.

O engajamento resulta de três situações psicológicas: significância psicológica (sentimento de que se está recebendo retorno em troca da energia física, cognitiva e emocional despendida no trabalho), disponibilidade psicológica (solicitude, associada à confiança, de um indivíduo para com seu empregador) e segurança psicológica (ligada à experiência de trabalhar sem temer constrangimentos diversos ou resultados negativos) (KAHN, 1990). De acordo com tal entendimento, é necessário que essas três condições psicológicas estejam presentes para que o indivíduo torne-se mais engajado (ARROWSMITH; PARKER, 2013).

Segundo Harrison, Newman e Roth (2006), o engajamento está ligado ao estilo de gestão dos líderes e ao ambiente organizacional. Quando esses dois elementos contribuem para a satisfação experimentada no trabalho, têm-se um contexto que favorece o engajamento do sujeito com suas atividades laborais (KATARIA; GARG; RASTOGI, 2013; SHUCK; REIO JÚNIOR, 2014; BAKKER; DEMEROUTI; SANZ-VERGEL, 2014).

Por outro lado, Olivier e Rothmann (2007) argumentam que as pessoas são naturalmente autoexpressivas e, quando desempenham funções que lhes permitam se comportar de uma maneira que reflita ou exprima seu autoconceito, tendem a atribuir maior sentido ou significado ao trabalho, o que leva à maior identificação com as atividades laborais e, consequentemente, a um maior engajamento.

\subsection{Exaustão no trabalho}

A exaustão no trabalho refere-se à sensação de desgaste físico e emocional que determinado indivíduo passa a sentir devido ao estresse ocupacional crônico (MASLACH; JACKSON, 1986). De acordo com Zohar (1997) e Cordes e Dougherty (1993), a exaustão emocional é o primeiro reflexo das situações de estresse com as quais os indivíduos se deparam em seu ambiente de trabalho, tais como a sobrecarga de atividades, os contatos interpessoais conflituosos e a relação de expectativas criadas por eles com relação ao seu rendimento dentro da organização. 
A exaustão emocional é apontada como o ponto de partida para o esgotamento profissional ou síndrome de Burnout, que se caracteriza também pela despersonalização e baixa realização pessoal, resultando em sentimentos e atitudes negativas do indivíduo (insatisfação, desgaste e perda do comprometimento) em relação às suas atividades laborais, afetando seu desempenho e gerando consequências negativas para a organização, tais como absenteísmo, rotatividade e baixa produtividade (CORDES; DOUGHERTY, 1993).

Segundo Maslach et al. (1982), a síndrome de Burnout tende a se limitar aos profissionais que atuam nas áreas da saúde, ensino e demais serviços que envolvem elevado contato humano, nas quais é comum o esgotamento emocional, despersonalização e baixa realização pessoal. Todavia, pesquisas posteriores concluíram que tal síndrome é comum em diversas profissões, e não se limitam àquelas cujas naturezas demandam amplo contato com outras pessoas (HOOPS, 1999).

Fernandes e Ferreira (2015), analisando os antecedentes da exaustão no âmbito organizacional, constataram que existe influência direta dos conflitos, sobrecarga, pressão no trabalho e estresse ocupacional sobre o esgotamento emocional dos indivíduos. Complementarmente, de acordo com Cordes e Dougherty (1993), a criação de grandes expectativas no que tange a desafios no trabalho, reconhecimento/recompensa, progressão na carreira, entre outros, seguida pela frustração das mesmas, tende a gerar estresse nos trabalhadores e, em alguns casos, levar ao desenvolvimento da síndrome de Burnout.

Em contrapartida, em contextos nos quais os indivíduos contam com elevado suporte de seus superiores hierárquicos e de grupos sociais externos à organização, a exaustão experimentada tende a ser menor (BAKKER; DEMEROUTI; SANZ-VERGEL, 2014).

À medida que os indivíduos apresentam maior exaustão, normalmente deixam de se engajar suas atividades laborais (MASLACH; LEITER, 1997), todavia o não engajamento não significa, necessariamente, desgaste físico ou emocional do sujeito, o que evidencia que se tratam de dois construtos distintos, e não de dois pontos extremos de uma mesma dimensão do comportamento humano no trabalho (BAKKER; DEMEROUTI; SANZ-VERGEL, 2014), apesar de haver uma relação inversamente proporcional entre ambos nos dois sentidos (SCHAUFELI; SALANOVA, 2011).

Para evitar a exaustão e ainda estimular o engajamento no trabalho, é importante criar um ambiente organizacional em que os indivíduos se sintam animados e dispostos (BAKKER; DEMEROUTI; SANZVERGEL, 2014). Para isso, podem ser adotadas práticas voltadas para a aproximação entre funcionários e supervisores, discussão e revisão de expectativas, avaliação de resultados, fornecimento de feedback e recompensa de desempenhos elevados (ARROWSMITH; PARKER, 2013; RASHEED;KHAN; RAMZAN, 2013).

Logo, observa-se que, dependendo das práticas de gestão de pessoas empregadas pelas organizações, é possível estimular que os funcionários se engajem no trabalho ou desgastá-los física e emocionalmente, levando, neste último caso, à síndrome de Burnout e suas consequências negativas, tanto para empregados quanto para empregadores (ALFES et al., 2013; RICH; LEPINE; CRAWFORD, 2010).

\section{Aspectos metodológicos}

A presente pesquisa pode ser classificada como descritiva, de natureza quantitativa, por ter como objetivo caracterizar o comportamento de determinado grupo, utilizando, para isso, técnicas padronizadas para coleta e análise de dados (GIL, 2008).

O método de pesquisa adotado foi a survey, que consiste na coleta de dados de indivíduos utilizando um instrumento estruturado (HAIR JUNIOR et al., 2005). Esse método foi escolhido por propiciar maior rapidez no levantamento de dados e permitir o acesso a uma amostra maior em um menor intervalo de tempo, além de viabilizar a aplicação de técnicas estatísticas para tratamento dos dados coletados. Tem-se como vantagem desse método também o fato de possuir contato direto com o objeto estudado, já que as informações são fornecidas pelo próprio público-alvo da pesquisa (GIL, 2008).

Para operacionalizar a coleta de dados, foi utilizado um questionário autoadministrado, estruturado com base na escala Likert de sete pontos. Essa escala tem como objetivo mensurar o grau de concordância dos respondentes em relação a cada questão de pesquisa, tendo seus extremos associados às opções "discordo totalmente" e "concordo totalmente" (HAIR JUNIOR et al., 2005). 
Para mensurar o grau de flexibilização do trabalho, utilizou-se o modelo de Ceribeli e Ferreira (2016), composto por nove questões. Para o engajamento dos indivíduos no trabalho, foi utilizada a Utrecht Work Engagement Scale, proposta por Schaufeli e Bakker (2003) e traduzida para o português pelo Grupo de Estudos e Pesquisas sobre Estresse e Burnout, em 2009, que contém nove questões e aborda três dimensões: vigor, dedicação e absorção. Finalmente, para mensurar a exaustão no trabalho, foram utilizadas nove questões retiradas do Maslach Burnout Inventory, proposto por Maslach e Jackson (1981).

É importante destacar que se optou pela versão reduzida da Utrecht Work Engagement Scale, pois, de acordo com Seppälä et al. (2009), possui uma estrutura mais consistente em relação à versão completa. Por sua vez, a opção por utilizar apenas nove das 22 questões originais do Maslach Burnout Inventory justifica-se pelo fato de que tal modelo abrange as três dimensões da síndrome de Burnout (desgaste emocional, despersonalização e sentimento de incompetência), enquanto este estudo trabalhou apenas com a dimensão ligada ao esgotamento emocional.

A população da pesquisa foi composta por habitantes das cidades de Mariana, Ouro Preto e Ouro Branco, todas localizadas no estado de Minas Gerais, que estavam empregados no momento da coleta de dados e que possuíam, no mínimo, cinco anos de experiência profissional, pois se partiu do pressuposto de que recém-ingressos no mercado de trabalho tenderiam a apresentar níveis pouco significativos de esgotamento mental.

Optou-se por focar a coleta de dados em indivíduos com ensino superior completo, pois normalmente atuam em cargos nos quais a flexibilização do trabalho é mais viável do ponto de vista da organização, ao contrário do que ocorre na maior parte das funções operacionais, que demandam que os profissionais estejam presencialmente no local de trabalho em horário pré-estabelecido.

Para selecionar os elementos que iriam compor a amostra da pesquisa, utilizou-se a técnica de amostragem por conveniência, devido a sua natureza dinâmica e de baixo custo (HAIR JUNIOR et al., 2005). Além disso, a opção por essa técnica de amostragem deve-se ao fato de que não seria possível conseguir uma relação de todos os elementos da população do estudo, inviabilizando a escolha aleatória das unidades amostrais (VIANA, 2011).

Com relação ao tamanho da amostra, seguiram-se as recomendações de Hair Junior et al. (2005), isto é, de que são necessárias, pelo menos, 10 observações para cada variável de pesquisa quando se pretende aplicar técnicas de estatística multivariada. Considerando que o estudo, originalmente, contou com 27 variáveis, definiu-se um grupo amostral composto por 270 respondentes, sendo este o número de questionários válidos obtidos.

A coleta de dados foi realizada presencialmente e de maneira on-line. De forma presencial, os questionários foram impressos e entregues em locais de grande fluxo de pessoas que se encaixavam no perfil definido, nas cidades cujos habitantes formaram a população do estudo. De forma on-line, os questionários foram disponibilizados nas redes sociais, utilizando-se plataformas como Linkedln e Facebook, e também foram enviados por e-mail.

Para análise dos dados, optou-se pela modelagem de equações estruturais, que permite identificar a relação entre as variáveis preditoras do estudo e as variáveis dependentes. Diferentemente da regressão múltipla, a modelagem possibilita que se trabalhe com mais de uma variável dependente no mesmo modelo (MARUYAMA, 1997).

Utilizaram-se duas técnicas de forma complementar: a análise fatorial confirmatória (AFC) e a análise de caminhos. A primeira foi empregada para agrupar as 27 variáveis observadas no estudo em três variáveis latentes, sendo uma exógena (flexibilização do trabalho) e duas endógenas (engajamento no trabalho e exaustão no trabalho). Paralelamente, a análise de caminhos foi empregada com o intuito de testar a relação entre as variáveis latentes, conforme as seguintes hipóteses de pesquisa:

$\mathrm{H}_{1}$ : A flexibilização do trabalho influencia o engajamento no trabalho.

$\mathrm{H}_{2}$ : A flexibilização do trabalho influencia a exaustão no trabalho.

$\mathrm{H}_{3}$ :O engajamento no trabalho influencia a exaustão no trabalho.

Tais hipóteses, que nortearam a construção do instrumento de coleta de dados, a definição da técnica de análise estatística a ser empregada e a discussão dos resultados obtidos, podem ser visualizadas na Figura 1. 
Figura 1: Modelo de relações proposto

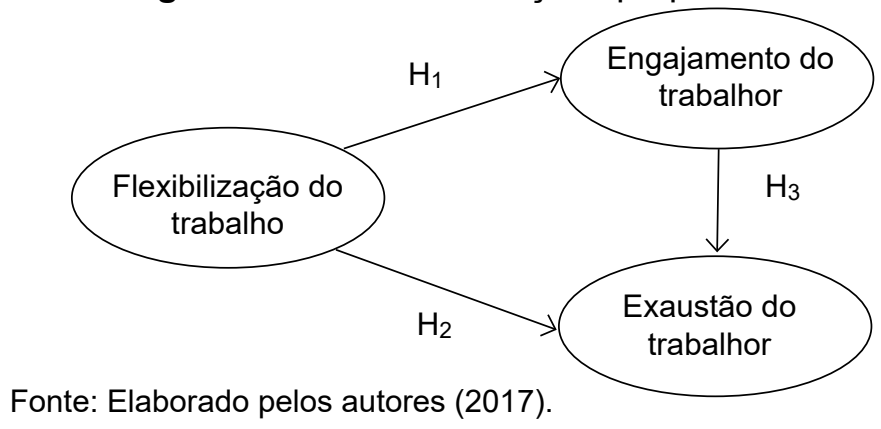

Ressalta-se que, para a execução da modelagem de equações estruturais, foi necessário selecionar o tipo de matriz de entrada dos dados a ser utilizado. Optou-se pela matriz de correlações, por ser de fácil interpretação e permitir que sejam analisadas as relações propostas entre os construtos (HAIR JUNIOR et al., 2009).

Por fim, cabe acrescentar que foram testados todos os pressupostos necessários à aplicação da técnica de modelagem de equações estruturais, que são a normalidade da distribuição das variáveis, a ausência de dados omissos e a inexistência de dados extremos (PILATI; LAROS, 2007).

\section{Resultados e discussão}

Primeiramente, com o intuito de agrupar as variáveis observadas do estudo em três variáveis latentes, representando os construtos flexibilização do trabalho, engajamento no trabalho e exaustão no trabalho, foi feito...? Analisaram-se os resultados obtidos na análise fatorial confirmatória.

Após a análise dos p-valores, adotando um nível de 95\% de confiança, decidiu-se pela exclusão de três variáveis observadas, relacionadas ao construto flexibilização do trabalho (FLEX7, FLEX8 e FLEX9), restando 24 das 27 variáveis originalmente incluídas na modelagem. Em seguida, rodou-se uma nova análise fatorial confirmatória, sendo obtidos somente $p$-valores menores que 0,05 , confirmando a significância estatística das relações entre as variáveis observadas e as variáveis latentes.

Posteriormente, analisaram-se as cargas fatoriais das variáveis agrupadas, cujos valores foram superiores a 0,7. Esse resultado, somado à significância estatística das relações testadas, valida as variáveis latentes criadas: flexibilização do trabalho, com seis variáveis observadas; engajamento no trabalho, com nove variáveis observadas; e exaustão no trabalho, com nove variáveis observadas, conforme Quadro 1.

Quadro 1: Variáveis latentes obtidas na análise fatorial exploratória

\begin{tabular}{|l|l|l|}
\hline Flexibilização do trabalho & Engajamento no trabalho & Exaustão no trabalho \\
\hline $\begin{array}{l}\text { FLEX1: Tenho possibilidade de realizar } \\
\text { parte de minhas atividades de trabalho em }\end{array}$ & ENGA1: Em meu trabalho, & EXAU1: Sinto-me emocionalmente \\
casa. & ENGA2: Em meu trabalho, & decepcionado com meu trabalho. \\
FLEX2: A organização onde trabalho & sinto-me com força e vigor. & de trabalho sinto-me esgotado. \\
adota mecanismos que permitem que & ENGA3: Estou entusiasmado & EXAU3: Quando me levanto pela manhã \\
os funcionários realizem parte de suas & com meu trabalho. & e me deparo com outra jornada de \\
atividades à distância. & ENGA4: Meu trabalho me & trabalho, já me sinto esgotado. \\
FLEX3: Minha rotina de trabalho permite & inspira. & EXAU4: Sinto que trabalhar todo o dia \\
que eu me desloque para a organização & ENGA5: Quando levanto pela & com pessoas me cansa. \\
apenas em dias específicos, pois posso & manhã tenho vontade de ir & EXAU5: Sinto que meu trabalho está me \\
realizar minhas tarefas fora dela. & trabalhar. & desgastando. \\
FLEX4: Tenho flexibilidade para alterar & ENGA6: Sinto-me feliz quando & EXAU6: Sinto-me frustrado com meu \\
minha jornada de trabalho diária (horário & trabalho intensamente. & trabalho. \\
de entrada e saída). & ENGA7: Estou orgulhoso com o & EXAU7: Sinto que estou trabalhando \\
FLEX5: Posso definir minha carga horária & trabalho que realizo. & demais. \\
de trabalho diária, desde que eu cumpra & ENGA8: Sinto-me envolvido & EXAU8: Sinto que trabalhar em contato \\
$\begin{array}{l}\text { a carga horária de trabalho mensal pré- } \\
\text { estabelecida pela organização. }\end{array}$ & com o trabalho que faço. & direto com as pessoas me estressa. \\
FLEX6: Tenho autonomia para definir meu \\
horário de trabalho & ENGA9: Deixo-me levar pelo & EXAU9: Sinto-me como se estivesse no \\
\end{tabular}

Fonte: Elaborado pelos autores (2017). 
Depois de validar a análise fatorial confirmatória, passou-se para a análise da qualidade do modelo de equações estruturais testado, que pode ser visualizado na Figura 2, sendo utilizados índices de ajuste absoluto, incremental e parcimonioso.

Figura 2: Modelo de equações estruturais testado

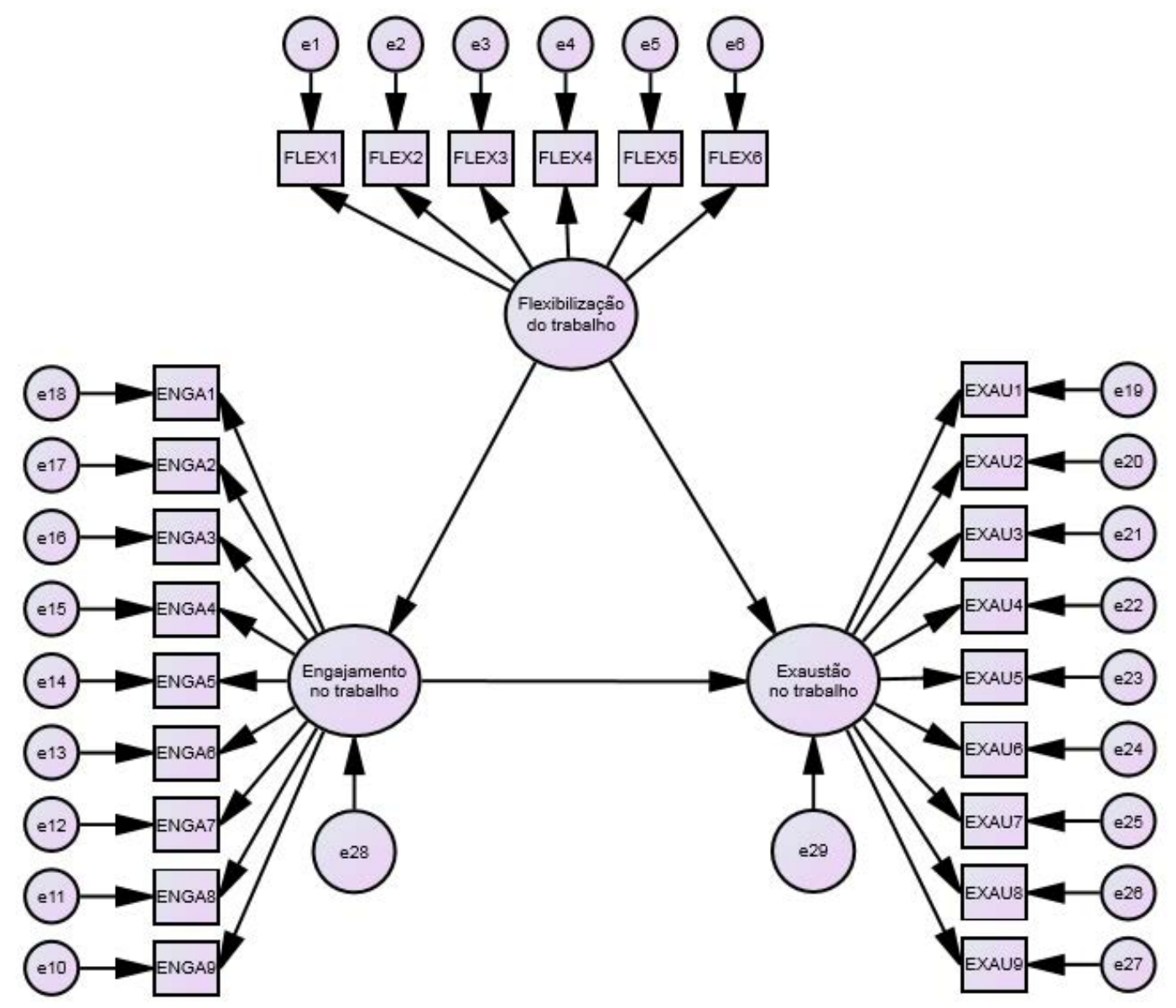

Fonte: Elaborado pelos autores (2017).

O ajuste absoluto, que representa o grau em que o modelo testado tem capacidade de explicar a matriz de correlações observada, foi avaliado utilizando-se a raiz do erro quadrático médio de aproximação (RMSEA - root mean square error of approximation), sendo considerados aceitáveis valores inferiores a 0,08 (HAIR JUNIOR et al., 2009; GARSON, 2012). O resultado do RMSEA do modelo proposto foi de 0,076, confirmando ajuste absoluto satisfatório, ou seja, há capacidade de previsão adequada da matriz de correlações observada.

Por sua vez, o ajuste incremental, que compara o modelo testado com um modelo de referência (modelo nulo), foi avaliado utilizando-se o índice de qualidade de ajuste calibrado (AGFI - adjusted goodness-of-fit index), cujo valor varia entre 0 e 1 , sendo recomendáveis valores iguais ou superiores a 0,8 (STACCIARINI; PACE, 2017). O resultado do AGFI foi de 0,793 , logo, o ajuste incremental obtido também pode ser considerado aceitável.

Por fim, o ajuste parcimonioso, que identifica se houve superajustamento dos dados em decorrência da existência de muitos coeficientes, foi avaliado utilizando-se a medida do qui-quadradonormado (CMIN/ DF), sendo considerados aceitáveis valores inferiores a 5,0 (JORESKOG, 1970). Como o qui-quadrado normado do modelo proposto foi de 2,7, conclui-se que não há superajustamento dos dados.

Após a análise dos três índices, concluiu-se que o modelo proposto apresenta uma qualidade de ajuste aceitável, validando-o. A seguir, prosseguiu-se para a análise de caminhos, que testou a relação entre as variáveis latentes criadas após a análise fatorial confirmatória, adotando-se um nível de confiança de $95 \%$. 
A primeira relação analisada, que representa a primeira hipótese da pesquisa, refere-se à influência que a variável latente exógena "flexibilização do trabalho" exerce sobre a variável latente endógena "engajamento no trabalho". Dado que o p-valor obtido foi de 0,606 , constatou-se que essa relação não é estatisticamente significativa. Logo, não foi possível confirmar $\mathrm{H}_{1}$.

A segunda relação analisada, que representa a segunda hipótese de pesquisa, refere-se à influência que a variável latente exógena "flexibilização do trabalho" exerce sobre a variável latente endógena "exaustão no trabalho". Dado que o $p$-valor encontrado foi de 0,074 , constatou-se que essa relação também não é estatisticamente significativa. Sendo assim, $\mathrm{H}_{2}$ também não foi confirmada.

Por fim, a terceira relação analisada representa a terceira hipótese de pesquisa, que se refere à influência que a variável latente endógena "engajamento no trabalho" exerce sobre a variável latente endógena "exaustão no trabalho". Dado que o p-valor obtido foi de 0,018 , constatou-se que essa relação, ao contrário das duas anteriores, apresenta significância estatística. Neste caso, aceitou-se $\mathrm{H}_{3}$.

No Quadro 2, encontram-se resumidos os resultados obtidos para cada uma das três hipóteses propostas nesta pesquisa.

Quadro 2: Testes das hipóteses da pesquisa

\begin{tabular}{lll}
\hline \multicolumn{1}{c}{ Hipótese } & P-valor obtido & \multicolumn{1}{c}{ Resultado } \\
\hline $\mathrm{H}_{1}$ : A flexibilização do trabalho influencia o engajamento no trabalho. & 0,606 & Não suportada \\
$\mathrm{H}_{2}$ : A flexibilização do trabalho influencia a exaustão no trabalho. & 0,074 & Não suportada \\
$\mathrm{H}_{3}$ : O engajamento no trabalho influencia a exaustão no trabalho. & 0,018 & Suportada \\
\hline
\end{tabular}

Fonte: Elaborado pelos autores (2017).

Ao término da análise dos resultados estatísticos encontrados, após a conclusão dos testes de hipóteses conduzidos, não foi possível confirmar que a flexibilização dos arranjos laborais nas organizações exerce um impacto direto sobre o grau de engajamento ou de exaustão apresentados pelos funcionários.

Contudo constatou-se que o engajamento do trabalhador tende a exercer um impacto negativo sobre a exaustão por ele experimentada no trabalho, considerando que o coeficiente beta encontrado para esta relação foi de $-0,55$.

Os resultados relativos à $H_{1}$ destoam daqueles alcançados por Timms et al. (2015) e Sardeshmukh, Sharma e Golden (2012), não sendo possível ratificar a relação por eles apontada entre a flexibilização dos arranjos laborais e a dedicação e vigor dos indivíduos para desempenharem os papéis exercidos na organização onde trabalham.

Por sua vez, os resultados relativos à $\mathrm{H}_{2}$ não corroboraram aqueles obtidos por Windeler, Chudoba e Sundrup (2017), Sardeshmukh, Sharma e Golden (2012) e Peters e Wildenbeest (2010), à medida que, ao contrário do que se verifica em tais estudos, não foi possível confirmar a influência exercida pela flexibilização laboral sobre o esgotamento dos trabalhadores.

Por fim, os resultados relativos à $\mathrm{H}_{3}$ complementam a constatação de Maslach e Leiter (1997) de que a exaustão afeta de forma negativa o engajamento do trabalhador, contribuindo para esclarecer que essa relação também existe no sentido inverso, ou seja, que o engajamento individual também afeta negativamente a exaustão experimentada pelo sujeito em suas atividades laborais, o que vem ao encontro do que afirmam Schaufeli e Salanova (2011).

Uma hipótese para explicar a falta de correlação entre a flexibilização dos arranjos laborais e a exaustão é que, em arranjos de home office, por exemplo, alguns indivíduos podem se sentir menos desgastados por terem a possibilidade de conciliar melhor os assuntos profissionais e os pessoais/familiares, enquanto outros podem trabalhar um número maior de horas em casa e enfrentar dificuldade para separarem o trabalho da vida pessoal, tornando-se, por conseguinte, mais fatigados. Portanto, o impacto desse tipo de política sobre o esgotamento dos trabalhadores pode ser muito variável.

Adicionalmente, uma hipótese para explicar a falta de correlação entre a flexibilização dos arranjos laborais e o engajamento é que tal estado mental pode estar ligado, principalmente, ao ambiente de 
trabalho, à identificação individual em relação ao trabalho executado e à organização, e à personalidade dos trabalhadores.

Finalizando, ao refletir acerca da influência negativa que o engajamento exerce sobre a exaustão, pode-se formular como hipótese que o trabalhador que se expressa em suas atividades laborais tende a alcançar maior autorrealização profissional e isto faz com que ele esteja menos sujeito ao esgotamento no trabalho.

\section{Conclusão}

Em decorrência do aumento da concorrência, dos crescentes avanços tecnológicos e das mudanças nos paradigmas gerenciais, a gestão de pessoas tem passado por inúmeras transformações, conceituais e na práxis. E, dentre as novas práticas adotadas, destaca-se a flexibilização dos arranjos laborais, cujos efeitos sobre as diferentes dimensões do comportamento humano no trabalho ainda carecem de investigação no campo da Ciência Administrativa. Nesse contexto, delimitou-se como objetivo para a presente pesquisa analisar a influência da flexibilização do trabalho sobre o engajamento e a exaustão emocional dos trabalhadores, assim como do engajamento sobre a exaustão.

Após a análise dos dados, não foi possível ratificar que existe uma relação significativa entre a adoção de arranjos laborais flexíveis por parte das organizações e o grau de engajamento e de exaustão apresentados pelos funcionários. Portanto, não se confirmou que práticas como home office, telework, redução da jornada e flexibilização dos horários de trabalho influenciam de maneira relevante a dedicação e o vigor ou o esgotamento mental dos profissionais.

Por outro lado, confirmou-se a relação testada entre o engajamento e a exaustão do trabalhador. Os resultados obtidos indicam que os profissionais mais engajados nas organizações são aqueles que estão menos sujeitos a experimentarem maior desgaste emocional em suas atividades laborais, reforçando estudos anteriores que constataram que existe uma relação significativa entre esses dois construtos.

Logo, conclui-se que os indivíduos que mobilizam seus melhores esforços e veem no trabalho uma forma de se expressarem fisicamente, emocionalmente e cognitivamente, mostrando disposição ao realizarem suas tarefas, tendem a preservar (e não a drenar) seus recursos mentais. Com isso, rompe-se com a ideia, que faz parte do senso comum, de que o esgotamento mental dos indivíduos é consequência da dedicação e do vigor direcionados por eles à execução de suas atividades no trabalho.

A partir desses resultados, constata-se que as organizações devem investir em mecanismos que promovam ou estimulem o engajamento de seus trabalhadores, o que remete a uma nova questão que precisa ser levantada: que tipos de políticas e práticas podem ser implantadas pelos gestores para que se alcance tal finalidade? Tal questionamento ainda carece de respostas na Ciência Administrativa, o que evidencia uma lacuna na literatura a ser sanada em estudos futuros.

Como limitações da pesquisa, pode-se citar que a coleta de dados se restringiu a apenas três cidades mineiras e que os questionários foram respondidos por profissionais que atuam em múltiplos contextos ( $p$. e. indústria da mineração, instituições financeiras, etc.), ou seja, as peculiaridades de cada um deles não foram consideradas na análise.

Assim sendo, sugere-se que novas pesquisas sejam realizadas abarcando outras regiões do país e contextos laborais específicos, como a indústria, o setor de serviços, o comércio, o setor bancário, etc., com o intuito de confirmar os resultados aqui obtidos e/ou de identificar determinadas especificidades regionais e/ou setoriais.

Para finalizar, destaca-se que este trabalho contribui para o avanço da compreensão acerca da relação entre o engajamento e a exaustão do trabalhador, duas dimensões diferentes do comportamento humano no trabalho até agora pouco exploradas na Ciência Administrativa, principalmente no Brasil.

\section{Referências}

ALFES, K. et al.. The link between perceived human resource management practices, engagement and employee behaviour: a moderated mediation model. The International Journal of Human Resource

Management, [s.I.], v. 24, n. 2, p. 330-351, 2013. 
ALMEIDA, M. I. R.; TEIXEIRA, M. L. M.; MARTINELLI, D. P. Por que administrar estrategicamente recursos humanos? Revista de Administração de Empresas, São Paulo, v. 33, n. 2, p. 12-24, Mar./ Abr.1993.

ARROWSMITH, J.; PARKER, J. The meaning of 'employee engagement'for the values and roles of the HRM function. The International Journal of Human Resource Management, [s.I.], v. 24, n. 14, p. 2692-2712, 2013.

BAJZIKOVA, L. et al.. Are flexible work arrangements attractive enough for knowledge-intensive businesses? Procedia-Social and Behavioral Sciences, [s.I.], v. 99, p. 771-783, 2013.

BAKKER, A. B.; DEMEROUTI, E.; SANZ-VERGEL, A. I. Burnout and work engagement: the JD-R approach. Annual Review of Organizational Psychology and Organizational Behavior, [s.I.], v. 1, p. 389-411, 2014.

BEN-AVI, N.; TOKER, S.; HELLER, D. "If stress is good for me, it's probably good for you too": stress mindset and judgment of others' strain. Journal of Experimental Social Psychology, [s.I.], v. 74, p. 98110, 2018.

CAMARGOS, M.A.; BARBOSA, F.V. Fusões, aquisições e takeovers: um levantamento teórico dos motivos, hipóteses testáveis e evidências empíricas. Caderno de Pesquisas em Administração, São Paulo, v. 10, n. 2, p. 17-38, abr./jun. 2003.

CERIBELI, H. B.; FERREIRA, F. J. R. Uma análise da relação entre flexibilização do trabalho, comprometimento organizacional e intenção de permanência na organização. Revista Globalización, Competitividad \& Gobernabilidad, Espanha, v. 10, n. 3, p. 37-56, sep.-dic. 2016.

COENEN, M.; KOK, R. A. Workplace flexibility and new product development performance: the role of telework and flexible work schedules. European Management Journal, [s.I.], v. 32, n. 4, p. 564-576, 2014.

COLE, R.; OLIVER, A.; BLAVIESCIUNAITE, A. The changing nature of workplace culture. Facilities, [s.I.], v. 32, n. 13/14, p. 786-800, 2014.

CORDES, C. L.; DOUGHERTY, T. W. A review and an integration of research on job burnout. Academy of Management Review, [s.I.], v. 18, n. 4, p. 621-656, 1993.

COSTA, S. A. C. Controle em novas formas de trabalho: teletrabalhadores e o discurso do empreendedorismo de si. Cadernos EBAPE.BR, Rio de Janeiro, v. 11, n. 3, artigo 8, p. 462-474, set./ nov. 2013.

DEDECCA, C. S. Racionalização econômica e trabalho no capitalismo avançado. Campinas: IEUnicamp, 1999.

FERNANDES, L. C.; FERREIRA, M. C. Qualidade de vida no trabalho e risco de adoecimento: estudo no poder judiciário brasileiro. Psicologia USP, São Paulo, v. 26, n. 2, p. 296-306, May/Aug.2015.

FLEURY, A.; FLEURY, M. T. L.; BORINI, F. M. The Brazilian multinationals' approaches to innovation. Journal of International Management, [s.I.], v. 19, n. 3, p. 260-275, 2013.

GARRETT, R. K.; DANZIGER, J. N. Which telework? Defining and testing a taxonomy of technologymediated work at a distance. Social Science Computer Review, [s.I.], v. 25, n. 1, p. 27-47, 2007.

GARSON, G. D. Testing statistical assumptions. Asheboro: Statistical Associates Publishing, 2012.

GENARI, D.; FACCIN, K.; MACKE, J. Mensuração do comprometimento organizacional em redes de indústrias vitivinícolas brasileiras. REAd-Revista Eletrônica de Administração, Porto Alegre, v. 19, n. 2 , maio/ago. 2013.

GIL, A. C. Métodos e técnicas de pesquisa social. 6. ed. São Paulo: Editora Atlas SA, 2008. 
GRISCI, C. L. I.; CARDOSO, J. Experimentação do tempo e estilo de vida em contexto de trabalho imaterial. Cadernos EBAPE.BR, Rio de Janeiro, v. 12, n. 4, p. 851-865, Out./Dez. 2014.

HAIR JUNIOR, J. F. et al. Fundamentos de métodos de pesquisa em Administração. Porto Alegre: Bookman, 2005.

HAIR JUNIOR. F. et al. Análise multivariada de dados. Porto Alegre: Bookman, 2009.

HALLIDAY, L. et al. Grit and burnout in UK doctors: a cross-sectional study across specialties and stages of training. Postgraduate Medical Journal, [s.I.], v. 93, n. 1101, p. 389-394, 2017.

HARRISON, D. A.; NEWMAN, D. A.; ROTH, P. L. How important are job attitudes? Meta-analytic comparisons of integrative behavioral outcomes and time sequences. Academy of Management Journal, [s.I.], v. 49, n. 2, p. 305-325, 2006.

HILL, J. E. et al. Defining and conceptualizing workplace flexibility. Community, Work and Family, [s.I.], v. 11, n. 2, p. 149-163, 2008.

HOOPS, B.K. Review of the truth about burnout: how organisations cause personal stress and what to do about it. Psychiatric Rehabilitation Journal, [s.I.], v. 23, n. 2, p. 194-195, 1999.

JÖRESKOG, K. G. A general method for estimating a linear structural equation system. ETS Research Report Series, New Jersey: Educational Testing Service , 1970, 43p.

KAHN, W. A. Psychological conditions of personal engagement and disengagement at work. Academy of Management Journal, NY - USA v. 33, n. 4, p. 692-724, 1990.

KARSTEN, L.; LEOPOLD, J. Time and management: the need for management. Personnel Review[s.I], v. 32, n. 4, p. 405-421, 2003. DOI: https://doi.org/10.1108/00483480310477506

KATARIA, A.; GARG, P.; RASTOGI, R. Employee engagement and organizational effectiveness: the role of organizational citizenship behavior. International Journal of Business Insights \& Transformation, [s.I], v. 6; n. 1, p. 102-113, 2013.

LEITE, N. P.; LEITE, F. P.; ALBUQUERQUE, L. G. A gestão de pessoas e as estratégias de atração, desenvolvimento e retenção de profissionais: o caso Petrobrás. Revista Ibero-Americana de Estratégia, São Paulo, v. 12, n. 4, p. 91-122, out./dez. 2013.

LEWIS, R.; DONALDSON-FEILDER, E.; THARANI, T. Management competencies for enhancing employee engagement. London: Chartered Institute of Personnel and Development, 2011.

MARUYAMA, G. Basics of structural equation modeling. Thousand Oaks: Sage Publications, 1997. MASCARENHAS, A. O.; BARBOSA, A. C.Q. Produção científica brasileira em gestão de pessoas no período 2000-2010. RAE-Revista de Administração de Empresas, São Paulo, v. 53, n. 1, jan./fev.2013.

MASLACH, C. Burnout: the cost of caring.Upper Saddle River -Nova Jérsei: Prentice Hall, 1982.

MASLACH, C.; JACKSON, S. E. The measurement of experienced burnout. Journal of Occupational Behavior, [s.I], v. 2, p. 99-113, 1981.

MASLACH, C.; JACKSON, S. E. Maslach Burnout Inventory. Palo Alto- Califórnia, EUA: Consulting Psychologists Press, 1986.

MASLACH, C.; LEITER, M. P. Trabalho: fonte de prazer ou desgaste. Campinas: Papirus, 1997. MENDONÇA, A. A. A crise econômica e a sua forma contemporânea. Lisboa: Caminho, 1990.

MENESES, M. P. P. et al. A produção científica brasileira sobre a gestão de recursos humanos de $2001 \mathrm{e}$ 2010. Revista de Administração Mackenzie, São Paulo, v. 15, n. 4, p. 111-134, jul./ago. 2014.

OLIVIER, A. L.; ROTHMANN, S. Antecedents of work engagement in a multinational company. SA Journal of Industrial Psychology, [s.I],v. 33, n. 3, p. 49-56, 2007. 
OUWENEEL, E.; LE BLANC, P. M.; SCHAUFELI, W. B. Do-it-yourself: an online positive psychology intervention to promote positive emotions, self-efficacy, and engagement at work. Career Development International, [s.I], v. 18, n. 2, p. 173-195, 2013.

PETERS, P.; WILDENBEEST, M. Telework as a job resource: a comparison of 'flow' and exhaustion among marginal and substantial teleworkers. Gedrag\&Organisatie, [s.I], v. 23, n. 2, p. 97-117, 2010.

PILATI, R.; LAROS, J. A. Modelos de equações estruturais em psicologia: conceitos e aplicações.

Psicologia, Teoria e Pesquisa, Brasília, v. 23, n. 2, p. 205-216, Abr-Jun, 2007.

PORTO-MARTINS, P. C.; BASSO-MACHADO, P. G.; BENEVIDES-PEREIRA, A. M. T. Engagement no trabalho: uma discussão teórica. Fractal, Revista de Psicologia, Niterói, v. 25, n. 3, p. 629-644, set./ dez.2013.

RAFALSKI, J. C.; ANDRADE, A. L. DevelopmentofthePerceptionsof Future RetirementScale (PFRS) andpsychosocialcorrelates. Psico-USF, Itatiba, v. 22, n. 1, p. 49-62, jan./apr. 2017.

RAFALSKI, J. C.; ANDRADE, A. L. Home-office: aspectos exploratórios do trabalho a partir de casa. TemasemPsicologia, Ribeirão Preto, v. 23, n. 2, p. 431-441, jun. 2015.

RASHEED, A.; KHAN, S.; RAMZAN, M. Antecedents and consequences of employee engagement: the case of Pakistan. Journal of Business Studies Quarterly, [s.I], v. 4, n. 4, p. 183-200, Oct . 2013.

RICH, B. L.; LEPINE, J. A.; CRAWFORD, E. R. Job engagement: antecedents and effects on job performance. Academy of Management Journal, [s.I], v. 53, n. 3, p. 617-635, Jun. 2010.

ROHM, R. H. D.; LOPES, N. F. O novo sentido do trabalho para o sujeito pós-moderno: uma abordagem crítica. Cadernos EBAPE. BR, Rio de Janeiro, v. 13, n. 2, p. 332-345, Abr./Jun. 2015.

SARDESHMUKH, S. R.; SHARMA, D.; GOLDEN, T. D. Impact of telework on exhaustion and job engagement: a job demands and job resources model. New Technology, Work and Employment, [s.I], v. 27, n. 3, p. 193-207, Nv. 2012.

SCHAUFELI, W. B.; BAKKER, A. Utrecht Work Engagement Scale (UWES). Utrecht: Occupational Health Psychology Unit, 2003.

SCHAUFELI, W.; SALANOVA, M. Work engagement: on how to better catch a slippery concept.

European Journal of Work and Organizational Psychology, [s.I], v. 20, n. 1, p. 39-46, Feb. 2011.

SEPPÄLÄ, P. et al. The construct validity of the Utrecht Work Engagement Scale: multisample and longitudinal evidence. Journal of Happiness Studies, [s.I], v. 10, n. 4, p. 459-481, Agu. 2009.

SHUCK, B.; REIO JÚNIOR, T. G. Employee engagement and wellbeing: a moderation model and implications for practice. Journal of Leadership \& Organizational Studies, [s.I], v. 21, n. 1, p. 43-58, Jul. 2014.

STACCIARINI, T. S. G.; PACE, A. E. Análise fatorial confirmatória da escala

Appraisal of Self Care Agency Scale - Revised. Revista Latino-Americana de Enfermagem, Ribeirão Preto - SP, v. 25, p. 1-9, 2017.

TIMMS, C. et al. Flexible work arrangements, work engagement, turnover intentions and psychological health. Asia Pacific Journalof Human Resources, [s.I], v. 53, n. 1, p. 83-103, Jan. 2015.

VASCONCELOS, I. F. F. G. et al. Resiliência organizacional e inovação sustentável: um estudo sobre o modelo de gestão de pessoas de uma empresa brasileira de energia. Cadernos EBAPE. BR, Rio de Janeiro, v. 13, n. 4, Artigo 13, p. 910-929, out./dez. 2015.

VASCONCELOS, P.; FURTADO, E.; PINHEIRO, P. R. An approach of multidisciplinary criteria for modeling alternatives of flexible working. Computers in Human Behavior, [s.I], v. 51, parte B, p. 10541060, Oct . 2015. 
VIANA, A. B. N. Pesquisa quantitativa aplicada ao varejo. In: MERLO, E. M. (org.). Administração de varejo com foco em casos brasileiros. Rio de Janeiro: LTC, 2011.Cap. 15.

WINDELER, J. B.; CHUDOBA, K. M.; SUNDRUP, R. Z. Getting away from them all: managing exhaustion from social interaction with telework. Journal of Organizational Behavior, [s.I], v. 38, n. 7, p. 977-995, Sep. 2017.

WONG, I. A.; WAN, Y. K. P.; GAO, J. H. How to attract and retain generation Y employees? An exploration of career choice and the meaning of work. Tourism Management Perspectives, [s.I], v. 23, p. 140-150, Jul. 2017.

XANTHOPOULOU, D.; BAKKER, A.; FISCHBACH, A. Work engagement among employees facing emotional demands: The role of personal resources. Journal of Personnel Psychology, [s.l], v. 12, n. 2, p. 74-84, 2013.

$\mathrm{XU}$, E.; HUANG, X.; ROBINSON, S. L. When self-view is at stake: responses to ostracism through the lens of self-verification theory. Journal of Management, [s.I], v. 42, n. 1, p. 1-21, Jan. 2015.

ZOHAR, D. Predicting burnout with a hassle-based measure of role demands. Journal of Organizational Behavior, [s.I], v. 18, p. 101-115, Mar. 1997.

Submetido em: 19/01/2018

Aceito em: 08/03/2019 